\title{
Determinants of uptake of malaria preventive interventions among pregnant women in eastern Uganda
}

\author{
Solomon Tsebeni Wafula ${ }^{1,2^{*}}$ (D, Hilbert Mendoza ${ }^{1,2}$, Aisha Nalugya $^{1}$, David Musoke ${ }^{1}$ and Peter Waiswa ${ }^{3}$
}

\begin{abstract}
Background: Consistent use of insecticide-treated nets (ITNs) and intermittent preventive treatment in pregnancy (IPTp) have been recommended as cost-effective interventions for malaria prevention during pregnancy in endemic areas. However, the coverage and utilization of these interventions during pregnancy in sub-Saharan Africa is still suboptimal. This study aimed to determine the uptake of IPTp and ITNs and associated factors among women during their recent pregnancy in Eastern Uganda.
\end{abstract}

Methods: This was a cross-sectional study conducted among 2062 women who had delivered within the last 12 months prior to the start of the study in three districts of Eastern Uganda. The primary outcomes were consistent ITN use and optimal uptake (at least 3 doses) of IPTp. A modified Poisson regression was used to examine the association between consistent ITN use and the uptake of optimal doses of IPTp with independent variables. Data were analysed using Stata 14 software.

Results: The level of uptake of IPTp3 (at least three doses) was 14.7\%, while IPTp2 (at least two doses) was 60.0\%. The majority (86.4\%) of mothers reported regularly sleeping under mosquito nets for the full duration of pregnancy. Uptake of IPTp3 was associated with engaging in farming (adjusted PR $=1.71,95 \% \mathrm{Cl}[1.28-2.28]$ ) or business (adjusted PR $=1.60,95 \% \mathrm{Cl}[1.05-2.44]$ ), and attending at least 4 antenatal care (ANC) visits (adjusted PR $=1.72,95 \%$ $\mathrm{Cl}$ [1.34-2.22]). On the other hand, consistent ITN use was associated with belonging to the fourth wealth quintile (adjusted $\mathrm{PR}=1.08,95 \% \mathrm{Cl}[1.02-1.14]$ ) or fifth wealth quintile (adjusted $\mathrm{PR}=1.08,95 \% \mathrm{Cl}[1.02-1.15]$ ), and attending at least 4 ANC visits (adjusted PR $=1.07,95 \% \mathrm{Cl}[1.03-1.11]$ ).

Conclusion: Uptake of IPTp3 and consistent ITN use during pregnancy were lower and higher than the current Ugandan national targets, respectively. Study findings highlight the need for more efforts to enhance utilization of ANC services, which is likely to increase the uptake of these two key malaria preventive measures during pregnancy.

Keywords: ITN use, IPTp3 uptake, Malaria preventive interventions, Pregnant women, Eastern Uganda

\section{Background}

Pregnant women are a high-risk group for malaria and may have adverse consequences if infected. Malaria during pregnancy increases the risk of maternal and fetal

*Correspondence: swafula@musph.ac.ug

1 Department of Disease Control and Environmental Health, Makerere University School of Public Health, Kampala, Uganda

Full list of author information is available at the end of the article anaemia, low birth weight, stillbirth, spontaneous abortion, and neonatal death [1]. The World Health Organization (WHO) estimates that 11 million pregnancies in moderate and high malaria transmission sub-Saharan African countries such as Uganda were exposed to malaria infection in 2018 [2]. Consequently, about 872,000 children were born with low birth weight and more than $40 \%$ of maternal anaemia cases due to malaria occurred in these countries [2]. In studies in Uganda, 
malaria prevalence among pregnant women ranges from 13.1 to $50.0 \%$ [3, 4], but can be as high as $80 \%$ in highly endemic regions [5].

The WHO recommends a three-pronged package consisting of intermittent preventive treatment in pregnancy (IPTp) with sulfadoxine-pyrimethamine (SP), use of insecticide-treated bed nets (ITNs), and effective case management of clinical malaria and anaemia in areas with moderate to high malaria transmission rates [2]. In highly malaria-endemic countries such as Uganda, intermittent preventive treatment in pregnancy with SP (IPTp-SP) is recommended to prevent the adverse consequences of malaria on maternal and fetal outcomes. In 2012, the WHO updated its recommendations on IPT-SP and now requires that at least three doses of SP be given to all pregnant women at each scheduled antenatal care (ANC) visit starting as early as possible in the second trimester and given at one-month intervals [6]. In Uganda, the target is to have $93 \%$ of pregnant women receive at least two doses of SP during antenatal care (ANC) visits, and $80 \%$ to receive at least 3 doses (optimal doses). The use of ITNs is also recommended for all pregnant women in malaria-endemic countries, and in Uganda, the Malaria Reduction Strategic Plan 2014-2020 set targets for $100 \%$ of the population including pregnant women to be distributed with ITNs, and up to $85 \%$ to be sleeping under ITNs the previous night by the end of 2020 [7].

Despite these set national targets, the uptake of at least three doses (optimal dose) of IPTp-SP in Uganda is low at $18 \%$ [8]. Regarding ITN use, $90 \%$ of households owned at least one ITN but $75 \%$ of pregnant women aged 15-49 years reported having slept under an ITN the previous night, according to the latest malaria indicator survey [9]. Utilization of these interventions may be more challenging in rural districts of the country due to poor access to health facilities and lack of information on these strategies [10]. This justifies the need to examine factors that could contribute to this underachievement. A review of literature of factors associated with utilization of these preventive measures in sub-Saharan Africa highlighted both health system related factors (anti-malarial drug stockouts, limited safe water at ANC clinics, unavailability of skilled attendants, poor health personnel attitudes and unavailability of ITNs) and individual factors (woman's knowledge, pregnancy and woman's economic and social position and religious practices) [11, 12]. However, there exists geographical variation (between country and in country differences) of these predictors thus justifying the need for this study. There is limited information on individual factors associated with the utilization of IPTp and ITNs in rural Uganda. The Eastern region of Uganda has one of the highest malaria prevalence rates in the country [9]. Understanding these factors can increase the uptake of IPTp and ITNs during pregnancy, and consequently reduce the malaria burden in Uganda. This study aimed to assess the level of uptake of IPTp and ITNs and associated factors among women during their recent pregnancy in Eastern Uganda.

\section{Methods}

\section{Study design and settings}

This was a cross-sectional study conducted in the districts of Iganga, Luuka and Buyende in eastern Uganda. This region is predominantly rural, cover an area of $3549.8 \mathrm{~km}^{2}$, and have an estimated population of $1,065,284$ inhabitants living in 208,030 households [13]. These districts are served by at least 75 government-run health facilities and several private not for profit (PNFP) health centres [14]. Malaria, which is mostly attributable to Plasmodium falciparum, is endemic in this area. The main economic activity in these districts is subsistence farming, but other occupations include small-scale businesses, such as fishing, grain milling, market vending, motorcycle transport and formal employment. The Basoga, a Bantu-speaking group, are the predominant ethnic group, which make up to $9 \%$ of Uganda's population [14].

\section{Study domain, eligibility and sampling}

The study units were households, and the study domain included women who had delivered in the last 12 months prior to the start of the study and were resident in the area. Mothers were included in the study whether the child was delivered preterm or full-term, and irrespective of the birth outcome (whether the baby was alive or dead). Those who had not lived in the community for at least 1 year were excluded from the study.

Data were collected from 2062 mothers in three health sub-districts (HSDs): Buyende, Luuka, and Iganga. Sixteen (16) sub-counties (6 in Buyende, 6 in Luuka, and 4 in Iganga) were proportionately selected from the HSDs. The sub-counties in each HSD were randomly selected and within each sub-county, one parish was randomly selected. Two villages were randomly selected from each parish, and a list of households with mothers who met the criteria were listed. Participants were sampled at the village level using simple random sampling from the village listing made with the aid of local council 1 (village) leader. From each selected village, at least 50 households were visited by the enumerators from which one eligible respondent was selected per household.

\section{Data collection and study variables}

This study utilized secondary data from a broader study entitled "Innovations for increasing access to integrated safe delivery, PMTCT and newborn care in Rural 
Uganda". An interviewer-administered structured questionnaire developed based on the literature on the uptake of IPTp-SP and ITNs among pregnant women was used to collect quantitative data. The original English questionnaire was translated to Lusoga, the local language spoken by the study participants. Data were collected on socio-demographic characteristics, uptake of IPTp-SP, ITNs, and frequency of ANC visits. Research assistants were trained on appropriate methods of data collection, and the tool appropriately piloted. The primary outcome variables of the study were consistent ITN use and optimal uptake of IPTp-SP which were self-reported. Consistent ITN use was defined as sleeping under an ITN every night for the full duration of the last pregnancy, while optimal uptake of IPTp-SP was defined as 3 or more doses received during pregnancy. The covariates (independent variables) included the timing of first ANC, number of ANC visits, sociodemographic characteristics (such as maternal age, marital status, level of education of women, occupation, household size, parity, and wealth (measured using a wealth asset index). The wealth quintiles were generated using principal component analysis based on the information collected on assets owned and household structure. The covariates used for this study were selected from critical review of related published literature $[11,12]$.

\section{Statistical analysis}

Data were analysed using Stata Version 14.0 (StataCorp, Texas, US). Descriptive statistics such as frequencies and percentages were used to present categorical data, while means and standard deviations were used where data were continuous. The associations between the outcome variables (consistent ITN use and uptake of 3 or more IPTp-SP doses) and explanatory variables were explored using modified Poisson regression. Initially, unadjusted prevalence ratios (PRs) were obtained for the association between each outcome and each predictor variable. Prevalence ratios were preferred over odds ratios since odds ratios would overestimate the effect size when outcomes are common (prevalence $>10 \%$ ) $[15,16]$, as was the case in the current study. All epidemiologically meaningful independent variables were considered for a fully saturated model. Interactions between predictor variables and the primary outcomes were as well examined. A stepwise backward elimination method was then applied, removing variables with the largest non-significant $p$ values, systematically until only significant variables and those that improved the fit of the model were retained. The prevalence ratios (PR) and 95\% confidence intervals are presented. A $p$-value of less than 0.05 was considered statistically significant.

\section{Results}

\section{Background characteristics of participants}

A total of 2062 women who had been pregnant in the past 12 months within 1 year preceding the survey participated. The mothers' ages ranged from 14 to 49 years, with a mean age of 25.8 years $(S D \pm 6.6)$. About threequarters of the participants, 1280 (62.1\%) had primary school as their highest level of education, and the majority 1894 (91.9\%) were married or cohabitating. More than half of all women 1101 (53.4\%) made their first antenatal care (ANC) visit after 12 weeks of gestation, while 1309 $(63.5 \%)$ had at least 4 ANC visits throughout the gestation period (Table 1).

\section{Utilization of malaria preventive strategies during pregnancy}

The majority of participants 1904 (92.3\%) reported using ITNs at least once, whereas $86.4 \%$ (1772/2052) reported using ITNs regularly for the full duration of their last pregnancy. Consistent ITN use was significantly higher in Iganga district $(89.8 \%)$, followed by Buyende $(86.7 \%)$, then Luuka district $(83.3 \%)$ ( $p$-value $=0.007)$. Regarding IPTp uptake, 289 (14.7\%) of the participants had used at least 3 doses of IPTp-SP, 1178 (60.0\%) received at least two doses, $1603(81.6 \%)$ at least one dose, and 361 (18.4\%) did not receive any dose of IPTp-SP during their last pregnancy.

\section{Predictors of use of ITNs during pregnancy}

The proportion of women who regularly used ITNs during their last pregnancy was 7\% lower in Luuka compared to Iganga district (adjusted $\mathrm{PR}=0.93,95 \% \mathrm{CI}$ [0.88-0.97]). Women belonging to the fourth (adjusted $\mathrm{PR}=1.08,95 \%$ CI [1.02-1.14]) and fifth (highest) (adjusted PR $=1.08,95 \%$ CI [1.02- 1.15]) wealth quintiles were each 1.08 more likely to report using ITNs regularly during pregnancy compared to those in the lowest quintile. Women who had at least 4 antenatal care visits had a 7\% higher likelihood of regularly sleeping under ITNs during pregnancy compared to those who had fewer than 4 visits (adjusted PR $=1.07,95 \%$ CI [1.03-1.11]) (Table 2).

\section{Predictors of optimal uptake of IPTp-SP during pregnancy} Multivariable regression showed that women who were farmers (Adjusted PR $=1.71$, 95\% CI [1.28-2.28]) and those engaged in business (Adjusted PR $=1.60,95 \% \mathrm{CI}$ [1.05-2.44]) were respectively 1.7 and 1.6 times more likely to receive at least 3 doses of IPTp-SP compared to housewives. Women who had attended at least 4 ANC visits had a $70 \%$ higher chance of receiving at least 3 doses of IPTp-SP compared to those who only attended ANC 3 times or less (Adjusted PR $=1.72$, 95\% CI [1.342.22]) (Table 3). 
Table 1 Socio-demographic characteristics of the study participants

\begin{tabular}{lll}
\hline Characteristic & $\begin{array}{l}\text { Number } \\
\text { of participants } \\
(\mathrm{N}=2062)\end{array}$ & Percentage (\%) \\
\hline
\end{tabular}

\begin{tabular}{|c|c|c|}
\hline \multicolumn{3}{|l|}{ Age in years } \\
\hline$<20$ & 353 & 17.1 \\
\hline $20-24$ & 623 & 30.2 \\
\hline $25-29$ & 452 & 21.9 \\
\hline $30-34$ & 296 & 14.3 \\
\hline$\geq 35$ & 226 & 11.0 \\
\hline Not stated & 112 & 5.4 \\
\hline \multicolumn{3}{|c|}{ Highest education level } \\
\hline None & 248 & 12.0 \\
\hline Primary & 1280 & 62.1 \\
\hline Post primary & 523 & 25.4 \\
\hline Not stated & 11 & 0.5 \\
\hline \multicolumn{3}{|l|}{ Parity } \\
\hline Primiparous & 362 & 17.6 \\
\hline $2-4$ & 916 & 44.4 \\
\hline$\geq 5$ & 776 & 37.6 \\
\hline Not stated & 8 & 0.4 \\
\hline \multicolumn{3}{|l|}{ Marital status } \\
\hline Married & 1894 & 91.9 \\
\hline Not married & 168 & 8.1 \\
\hline \multicolumn{3}{|l|}{ Occupation } \\
\hline Farmer & 1218 & 59.1 \\
\hline Housewife & 554 & 26.9 \\
\hline Business & 181 & 8.8 \\
\hline Other $^{\mathrm{a}}$ & 109 & 5.3 \\
\hline \multicolumn{3}{|c|}{ Timing of first ANC visit (weeks) } \\
\hline$\leq 12$ & 947 & 45.9 \\
\hline$>12$ & 1101 & 53.4 \\
\hline Not stated & 14 & 0.7 \\
\hline \multicolumn{3}{|c|}{ Number of ANC visits } \\
\hline $1-3$ & 710 & 34.4 \\
\hline$\geq 4$ & 1309 & 63.5 \\
\hline Not stated & 43 & 2.1 \\
\hline
\end{tabular}

ANC antenatal care

a Other occupations included salaried work, casual labourers

\section{Discussion}

This study investigated the uptake of IPTp and ITNs, and associated factors among women during their recent pregnancy in Eastern Uganda. Findings show that the level of uptake of IPTp3 (14.7\%) was lower than that of consistent ITN use (86.4\%). The study also revealed that consistent ITN use was associated with wealth index and ANC attendance of at least 4 times while uptake of IPTp3 was influenced by mother's occupation and ANC attendance of at least 4 times.
While the study indicated high levels of ANC attendance, $\geq 4$ visits $(63.5 \%)$, the uptake of optimal doses of IPTp (14.7\%) was lower than the national target of $80 \%$ [7] and current national coverage of $18.5 \%$ [8]. These findings concur with those of a study conducted in Tanzania, where only $11 \%$ of the women had received optimal doses of IPTp during pregnancy [17]. However, higher coverage was reported in a study conducted in Ghana, where $71 \%$ of the pregnant women received the optimal doses of IPTp [18]. The low uptake indicated in this study could be due to missed opportunities to administer IPTp due to regular stock-out of SP, which has been reported in the literature as one of the major barriers to IPTp uptake at health facilities in Uganda [11]. In addition, sub-optimal ANC attendance by pregnant women could contribute to the low utilization of IPTp. For instance, pregnant women attending ANC only during the first trimester when IPTp is not supposed to be administered affects uptake of the intervention. Therefore, such health systems barriers to ANC need to be addressed which in turn are likely to increase utilization of IPTp.

A significant proportion of participants (92.3\%) reported using ITNs at least once during their last pregnancy, and $86.4 \%$ reported using ITNs regularly during the entire pregnancy. The high uptake of ITNs in this study could be attributed to existing strategies in Uganda such as ITN mass distribution campaigns among high-risk populations including pregnant women. Existing data indicate that utilization and ownership of ITNs has substantially improved owing to such campaigns in many countries in sub-Saharan Africa [19]. Similar findings were shown in a study conducted in the Democratic Republic of Congo, where $78.2 \%$ reported sleeping under ITNs regularly [20]. Lower rates of usage were however reported in a study conducted in Gulu district in Northern Uganda where only $35 \%$ of the pregnant women used ITNs [21]. This low utilization of ITNs in Northern Uganda could be because the study was conducted in an internally displaced peoples (IDP) camp, where the exchange and selling of ITNs to meet other immediate basic needs such as food is a common practice [21, 22]. Increased national campaigns on the use of ITNs by the Ministry of Health and other stakeholders is likely to further increase their utilization including among pregnant women in Uganda.

In this study, women who had at least 4 ANC visits had a 7\% higher likelihood of consistently sleeping under ITNs during pregnancy compared to those who had less than 4 visits. These findings are similar to those of a study conducted in Ethiopia where the number of ANC visits was found to be significantly associated with the utilization of ITNs [23]. This finding could be because pregnant women who frequently attend ANC are likely to be 
Table 2 Crude and adjusted analysis of predictors of consistent ITN use during pregnancy

\begin{tabular}{|c|c|c|c|c|c|c|}
\hline \multirow[t]{2}{*}{ Characteristic } & \multicolumn{2}{|c|}{ Uptake of ITNs n (\%) } & \multirow[t]{2}{*}{ Crude PR $[95 \% \mathrm{Cl}]$} & \multirow[t]{2}{*}{$p$-value } & \multirow[t]{2}{*}{ Adjusted PR [95\% Cl] } & \multirow[t]{2}{*}{$P$-value } \\
\hline & Consistent & Not consistent & & & & \\
\hline \multicolumn{7}{|l|}{ District } \\
\hline Iganga & $360(90.2)$ & $39(9.8)$ & 1 & & 1 & \\
\hline Luuka & $686(83.8)$ & $133(16.3)$ & $0.93[0.89-0.97]$ & 0.001 & $0.93[0.88-0.97]$ & 0.001 \\
\hline Buyende & $723(87.0)$ & $108(13.0)$ & $0.96[0.92-1.00]$ & 0.087 & $0.98[0.94-1.02]$ & 0.386 \\
\hline \multicolumn{7}{|l|}{ Age in years } \\
\hline$<20$ & $295(84.0)$ & $56(16.0)$ & 1 & & & \\
\hline $20-24$ & $516(83.5)$ & $102(16.5)$ & $0.99[0.94-1.05]$ & 0.823 & & \\
\hline $25-29$ & $406(89.8)$ & $46(10.2)$ & $1.07[1.01-1.13]$ & 0.018 & & \\
\hline $30-34$ & $263(89.5)$ & $31(10.5)$ & $1.06[1.00-1.13]$ & 0.042 & & \\
\hline$\geq 35$ & $198(88.0)$ & $27(12.0)$ & $1.05[0.98-1.12]$ & 0.175 & & \\
\hline \multicolumn{7}{|l|}{ Marital status } \\
\hline Married & 1635(86.7) & $250(13.3)$ & 1 & & & \\
\hline Not married & $137(82.0)$ & $30(18.0)$ & $0.95[0.88-1.02]$ & 0.135 & & \\
\hline \multicolumn{7}{|l|}{ Education level } \\
\hline None & $208(84.2)$ & $39(15.8)$ & 1 & & & \\
\hline Primary & $1099(86.2)$ & $176(13.8)$ & $1.02[0.97-1.09]$ & 0.433 & & \\
\hline Post primary & $455(87.7)$ & $64(12.3)$ & $1.04[0.98-1.11]$ & 0.210 & & \\
\hline \multicolumn{7}{|c|}{ Husband education level } \\
\hline None & $215(83.7)$ & $42(16.3)$ & 1 & & & \\
\hline Primary & $827(87.1)$ & $122(12.9)$ & $1.04[0.98-1.11]$ & 0.177 & & \\
\hline Post primary & $617(86.9)$ & $93(13.1)$ & $1.04[0.98-1.10]$ & 0.223 & & \\
\hline \multicolumn{7}{|l|}{ Parity } \\
\hline Primiparous & $298(83.0)$ & $61(17.0)$ & 1 & & & \\
\hline $2-4$ & $782(85.8)$ & $129(14.2)$ & 1.03 [0.98-1.09] & 0.221 & & \\
\hline$\geq 5$ & $685(88.5)$ & 89 (11.5) & $1.06[1.01-1.12]$ & 0.018 & & \\
\hline \multicolumn{7}{|l|}{ Occupation } \\
\hline Housewife & $483(87.5)$ & $69(12.5)$ & 1 & & & \\
\hline Peasant farmer & 1040 (86.0) & $170(14.0)$ & $0.98[0.94-1.02]$ & 0.368 & & \\
\hline Business & $156(86.2)$ & $25(13.8)$ & $0.99[0.92-1.05]$ & 0.655 & & \\
\hline Other occupation & $93(85.3)$ & $16(14.7)$ & $0.98[0.90-1.06]$ & 0.556 & & \\
\hline \multicolumn{7}{|l|}{ Household size } \\
\hline $1-4$ & $606(83.8)$ & $117(16.2)$ & $0.96[0.91-1.01]$ & 0.112 & & \\
\hline $5-8$ & $863(87.8)$ & 120 (12.2) & $1.00[0.96-1.05]$ & 0.847 & & \\
\hline$>8$ & $298(87.4)$ & $43(12.6)$ & 1 & & & \\
\hline \multicolumn{7}{|l|}{ Wealth index } \\
\hline 1 (lowest) & $338(83.5)$ & $67(16.5)$ & 1 & & 1 & \\
\hline 2 & $363(85.4)$ & $62(14.6)$ & $1.02[0.97-1.09]$ & 0.438 & 1.03 [0.97-1.09] & 0.325 \\
\hline 3 & 368 (85.6) & $62(14.4)$ & $1.03[0.97-1.09]$ & 0.397 & $1.03[0.97-1.10]$ & 0.271 \\
\hline 4 & 334 (88.6) & $43(11.4)$ & $1.06[1.00-1.12]$ & 0.038 & 1.08 [1.02-1.14] & 0.009 \\
\hline 5 (highest) & $342(89.5)$ & $40(10.5)$ & $1.07[1.02-1.13]$ & 0.013 & 1.08 [1.02-1.15] & 0.010 \\
\hline \multicolumn{7}{|c|}{ Timing of first ANC visit (weeks) } \\
\hline$\leq 12$ & $834(88.4)$ & 109 (11.6) & 1 & & & \\
\hline$>12$ & $928(84.8)$ & $167(15.3)$ & $0.96[0.93-0.99]$ & 0.014 & & \\
\hline \multicolumn{7}{|l|}{ Number of ANC visits } \\
\hline $1-3$ & $586(83.0)$ & $120(17.0)$ & 1 & & 1 & \\
\hline$>4$ & $1154(88.6)$ & 149(11.4) & $1.07[1.03-1.11]$ & 0.001 & $1.07[1.03-1.11]$ & 0.001 \\
\hline
\end{tabular}

Italic values indicate the significance of $\mathrm{p}$-value ( $\mathrm{p}$-value $<0.05)$ $A N C$ antenatal care, $C l$ confidence interval, $P R$ prevalence ratio 
Table 3 Predictors of uptake of 3 or more doses of IPTp-SP during pregnancy

\begin{tabular}{|c|c|c|c|c|c|c|}
\hline \multirow[t]{2}{*}{ Characteristic } & \multicolumn{2}{|c|}{ Uptake of IPTp-SP } & \multirow[t]{2}{*}{ Crude PR $[95 \% \mathrm{Cl}]$} & \multirow[t]{2}{*}{$p$-value } & \multirow[t]{2}{*}{ Adjusted PR $[95 \% \mathrm{Cl}]$} & \multirow[t]{2}{*}{ P-value } \\
\hline & $\geq 3$ doses $(\%)$ & $<3$ doses $(\%)$ & & & & \\
\hline \multicolumn{7}{|l|}{ District } \\
\hline Iganga & $51(13.4)$ & $330(86.6)$ & 1 & & & \\
\hline Luuka & $147(18.6)$ & $642(81.4)$ & $1.39[1.04-1.87]$ & 0.028 & & \\
\hline Buyende & $91(11.5)$ & $701(88.5)$ & $0.86[0.62-1.18]$ & 0.350 & & \\
\hline \multicolumn{7}{|l|}{ Age in years } \\
\hline$<20$ & $48(14.0)$ & $294(86.0)$ & 1 & & & \\
\hline $20-24$ & $93(15.6)$ & $503(84.4)$ & $1.11[0.81-1.53]$ & 0.519 & & \\
\hline $25-29$ & $69(15.9)$ & $365(84.1)$ & $1.13[0.81-1.59]$ & 0.472 & & \\
\hline $30-34$ & $26(9.4)$ & $253(90.6)$ & $0.67[0.42-1.05]$ & 0.077 & & \\
\hline$\geq 35$ & $27(12.7)$ & $185(87.3)$ & $0.91[0.58-1.41]$ & 0.665 & & \\
\hline \multicolumn{7}{|l|}{ Marital status } \\
\hline Married & $259(14.4)$ & $1546(85.6)$ & 1 & & & \\
\hline Not married & $30(18.9)$ & $129(81.1)$ & $1.31[0.93-1.85]$ & 0.1161 & & \\
\hline \multicolumn{7}{|l|}{ Education level } \\
\hline None & $27(11.6)$ & $206(88.4)$ & 1 & & & \\
\hline Primary & $175(14.3)$ & $1049(85.7)$ & $1.23[0.84-1.80]$ & 0.279 & & \\
\hline Post primary & $87(17.5)$ & $410(82.5)$ & $1.51[1.01-2.26]$ & 0.045 & & \\
\hline \multicolumn{7}{|c|}{ Husband education level } \\
\hline None & $28(11.7)$ & $212(88.3)$ & 1 & & & \\
\hline Primary & $122(13.5)$ & $782(86.5)$ & $1.16[0.79-1.70]$ & 0.459 & & \\
\hline Post primary & $117(16.9)$ & $575(83.1)$ & $1.45[0.99-2.13]$ & 0.059 & & \\
\hline \multicolumn{7}{|l|}{ Parity } \\
\hline Primiparous & $52(15.1)$ & $293(84.9)$ & 1 & & & \\
\hline $2-4$ & $147(16.7)$ & $733(83.3)$ & 1.11 [0.83-1.48] & 0.488 & & \\
\hline$\geq 5$ & $90(12.3)$ & $642(87.7)$ & $0.82[0.59-1.12]$ & 0.207 & & \\
\hline \multicolumn{7}{|l|}{ Occupation } \\
\hline Housewife & $52(9.8)$ & $481(90.2)$ & 1 & & 1 & \\
\hline Peasant farmer & $193(16.7)$ & $961(83.3)$ & $1.71[1.28-2.29]$ & $<0.001$ & $1.71[1.28-2.28]$ & $<0.001$ \\
\hline Business & $28(16.3)$ & $144(83.7)$ & $1.67[1.09-2.56]$ & 0.019 & $1.60[1.05-2.44]$ & 0.031 \\
\hline Other occupation & $16(15.2)$ & 89 (84.8) & $1.56[0.93-2.62]$ & 0.093 & $1.47[0.86-2.52]$ & 0.158 \\
\hline \multicolumn{7}{|l|}{ Household size } \\
\hline $1-4$ & $108(15.5)$ & $589(84.5)$ & $1.25[0.89-1.75]$ & 0.194 & & \\
\hline $5-8$ & $141(15.0)$ & $799(85.0)$ & $1.21[0.87-1.68)]$ & 0.252 & & \\
\hline$>8$ & $40(12.4)$ & $283(87.6)$ & & & & \\
\hline \multicolumn{7}{|l|}{ Wealth index } \\
\hline 1 (lowest) & 49 (12.7) & $336(87.3)$ & 1 & & & \\
\hline 2 & $56(13.7)$ & $354(86.3)$ & $1.07[0.75-1.53]$ & 0.699 & & \\
\hline 3 & $52(12.4)$ & 368 (87.6) & $0.97[0.68-1.40]$ & 0.882 & & \\
\hline 4 & $52(14.5)$ & $306(85.5)$ & 1.14 [0.79-1.64] & 0.475 & & \\
\hline 5 (highest) & 71 (19.7) & $289(80.3)$ & $1.55[1.10-2.17]$ & 0.010 & & \\
\hline \multicolumn{7}{|c|}{ Timing of first ANC visit (weeks) } \\
\hline$\leq 12$ & $152(16.8)$ & $753(83.2)$ & 1 & & & \\
\hline$>12$ & $137(13.0)$ & $921(87.1)$ & $0.77[0.62-0.95]$ & 0.017 & & \\
\hline \multicolumn{7}{|l|}{ Number of ANC visits } \\
\hline $1-3$ & $69(10.0)$ & $620(90.0)$ & 1 & & 1 & \\
\hline $4+$ & $216(17.2)$ & $1040(82.8)$ & $1.72[1.33-2.22]$ & $<0.001$ & $1.72[1.34-2.22]$ & $<0.001$ \\
\hline
\end{tabular}

Italic values indicate the significance of $\mathrm{p}$-value ( $\mathrm{p}$-value $<0.05$ )

$A N C$ antenatal care, $C l$ confidence interval, $P R$ prevalence ratio 
exposed to vital health related information on ITN usage, which leads to regular use of ITNs. Attending ANC also provide opportunities for receiving free ITNs from the Ministry of Health particularly at public healthcare facilities in Uganda. Indeed, previous studies have indicated that a significant proportion of pregnant women obtain ITNs from health facilities through ANC visits [11, 24]. Therefore, early and frequent ANC visits should be emphasized during pregnancy in order to provide opportunities for timely delivery of interventions, such as ITNs.

It was revealed that women belonging to the fourth and fifth wealth quintiles were 1.08 times more likely to report using ITNs consistently during pregnancy compared to those in the lowest quintile. This could be because women from a household with a higher wealth quintile are more likely to afford the costs associated with access to maternal health services including transportation costs incurred during ANC visits, and purchasing of ITNs. According to the 2016 Uganda Demographic Health Survey, a significant number of people obtain ITNs from shops/markets [24], implying that women belonging to a lower wealth quintile might not afford to buy these nets $[25,26]$. Increase in household wealth as well as economic empowerment of women and their families is expected to increase access to and utilization of malaria prevention interventions among pregnant women including ITNs.

Regarding IPTp, women who had attended at least 4 ANC visits had a 70\% higher chance of receiving optimal doses of IPTp-SP compared to those who only attended ANC 3 times or less. Similarly, data from the latest Uganda Demographic and Health survey indicated that the likelihood of taking optimal doses of IPTp-SP was increased among those who attended ANC $\geq 4$ times [24]. These findings corroborate those of a study conducted in Ghana where women who attended ANC 4 or more times were found to be positively associated with the uptake of optimal doses of SP [18]. This could be because optimal ANC visits present a good opportunity for timely and appropriate delivery of interventions, including administering IPTp-SP among pregnant women. Therefore, interventions targeted at improving timely ANC attendance are crucial in increasing IPTp uptake hence should be enhanced by the Ministry of Health, Uganda. It was also found that unlike housewives, businesswomen and peasant farmers were more likely to have higher IPTp use, but not insecticide-treated net use. Businesswomen earn from their businesses and can potentially afford buying IPTp or transport to the nearby facilities to get IPTp while peasants may have adequate time to attend the facilities. On the other hand, all households are supplied with nets free of charge through a mass distribution programme targeting pregnant women and children less than 5 years, through a community-based subsidized net distribution program. Its no wonder that no differences existed regardless of the occupation status. Ownership of nets is good indicator that mothers will use them [27].

This study had some limitations for example the outcomes were self-reported hence potential for social desirability bias. Secondly, the study utilized secondary data thus important information on important covariates including the knowledge of the mother on ITN and IPTp was not available. Finally, the study being cross-sectional in nature, hence causal inference cannot be inferred. However, due to the large sample size and wide scope of districts involved in the study, the results can be generalized to the eastern region of Uganda and other similar settings. In addition, the current study findings can inform design of future longitudinal and interventional studies aimed at understanding the causal factors related to optimal IPTp uptake and ITN use in this region.

\section{Conclusions}

The level of uptake of IPTp was below recommended guidelines. Fortunately, the consistent use of ITNs was slightly above the national target of $85 \%$. The study findings highlight the need to encourage optimal ANC visits which may in turn increase the uptake of both preventive measures. Economic empowerment of women and their households is likely to increase uptake of malaria prevention interventions among pregnant women including ITNs.

\section{Abbreviations}

ANC: Antenatal care; HSD: Health sub district; IPTp: Intermittent preventive treatment in pregnancy; IPTp -SP: Intermittent preventive treatment in pregnancy with sulfadoxine pyrimethamine; ITN: Insecticide treated net; PNFP: Private not for profit; PR: Prevalence ratio; WHO: World Health Organization.

\section{Acknowledgements}

We would like to thank the study participants for sparing their time to respond to the data collection tools. We also thank the district and local area authorities for their cooperation and support during data collection. Special thanks also go to the research assistants for their invaluable effort in collecting the data.

\section{Authors' contributions}

PW and STW conceived and designed the study. STW and HM analysed the data. HM, STW, AN and DM reviewed the analysis and wrote the first draft of the manuscript. PW acquired funding for the study. All authors read and approved the final manuscript.

\section{Funding}

This study was funded by World Health Organization (WHO) and Department for International Development (DFID). The funders had no role in study design, data collection and analysis, decision to publish, or preparation of the manuscript.

\section{Availability of data and materials}

The dataset used during the current study is available from the corresponding author on reasonable request. 


\section{Ethics approval and consent to participate}

Ethical clearance was obtained from the Makerere University School of Public Health Higher Degrees and Research Ethics Committee (HDREC) and the WHO Ethical Review Committee. Permission was also obtained from the district authorities of the study areas. Written informed consent was obtained from all participants and confidentially was highly observed.

\section{Consent for publication}

Not applicable.

\section{Competing interests}

The authors declare that they have no competing interests.

\section{Author details}

${ }^{1}$ Department of Disease Control and Environmental Health, Makerere University School of Public Health, Kampala, Uganda. ${ }^{2}$ Department of Epidemiology and Social Medicine, Faculty of Medicine and Health Sciences, University of Antwerp, Antwerp, Belgium. ${ }^{3}$ Department of Health Policy, Planning and Management, Makerere University School of Public Health, Kampala, Uganda.

Received: 17 April 2020 Accepted: 18 December 2020

Published online: 03 January 2021

\section{References}

1. Desai M, ter Kuile FO, Nosten F, McGready R, Asamoa K, Brabin B, et al. Epidemiology and burden of malaria in pregnancy. Lancet Infect Dis. 2007;7:93-104.

2. WHO. World malaria report 2019. Geneva, World Health Organization 2019. [https://www.who.int/publications-detail/world-malaria-repor t-2019].

3. Namusoke F, Rasti N, Kironde F, Wahlgren M, Mirembe F. Malaria burden in pregnancy at Mulago National Referral Hospital in Kampala. Uganda. Malar Res Treat. 2010;2010:913857.

4. Mbonye AK, Bygbjerg IC, Magnussen P. Intermittent preventive treatment of malaria in pregnancy: a new delivery system and its effect on maternal health and pregnancy outcomes in Uganda. Bull World Health Organ. 2008;86:93-100.

5. Okiring J, Olwoch P, Kakuru A, Okou J, Ochokoru H, Ochieng TA, et al. Household and maternal risk factors for malaria in pregnancy in a highly endemic area of Uganda: a prospective cohort study. Malar J. 2019;18:144.

6. WHO. Intermittent preventive treatment of malaria in pregnancy using sulfadoxine-pyrimethamine (IPTp-SP): Updated WHO Policy. Geneva, World Health Organization; 2012.

7. Ministry of Health. The Uganda Malaria Reduction Strategic Plan 20142020. Uganda: Kampala; 2014

8. Okethwangu D, Opigo J, Atugonza S, Kizza CT, Nabatanzi M, Biribawa $C$, et al. Factors associated with uptake of optimal doses of intermittent preventive treatment for malaria among pregnant women in Uganda: analysis of data from the Uganda Demographic and Health Survey, 2016. Malar J. 2019;18:250

9. Uganda Bureau of Statistics, ICF. Uganda Malaria Indicator Survey 2014-2015: Key Indicators. Kampala, Uganda, and Rockville, USA; 2015.

10. Maternal mortality. Key facts. [http://www.who.int/mediacentre/facts heets/fs348/en/].

11. Muhumuza E, Namuhani N, Balugaba BE, Namata J, Kiracho EE. Factors associated with use of malaria control interventions by pregnant women in Buwunga subcounty, Bugiri District. Malar J. 2016;15:342.
12. Hill J, Hoyt J, van Eijk AM, D'Mello-Guyett L, ter Kuile FO, Steketee R, et al. Factors affecting the delivery, access, and use of interventions to prevent malaria in pregnancy in sub-Saharan Africa. a systematic review and meta-analysis. PLoS Med. 2013;10:e1001488.

13. Uganda Bureau of Statistics. National population and housing census 2014 provisional results. Kampala: Ministry of Planning and Regional Development; 2014.

14. Uganda Bureau of Statistics. 2014 statistical abstract. Kampala, 2014.

15. Schmidt CO, Kohlmann T. When to use the odds ratio or the relative risk? Int J Public Health. 2008;53:165-7.

16. Zou G. A modified Poisson regression approach to prospective studies with binary data. Am J Epidemiol. 2004;159:702-6.

17. Sambili B, Kimambo R, Peng Y, Ishunga E, Matasha E, Matumu G, et al. Factors influencing anti-malarial prophylaxis and iron supplementation non-compliance among pregnant women in Simiyu Region, Tanzania. Int J Environ Res Public Health. 2016;13:626.

18. Ibrahim H, Maya ET, Issah K, Apanga PA, Bachan EG, Noora CL. Factors influencing uptake of intermittent preventive treatment of malaria in pregnancy using sulphadoxine pyrimethamine in Sunyani Municipality, Ghana. Pan Afr Med J. 2017:28:122.

19. Taylor CA, Florey L, Yé Y. Increasing equity of insecticide-treated net ownership in sub-Saharan Africa from 2003 to 2014. USAID: ICF Int; 2015.

20. Song JS, Paul MM, Dhakal S, Smith MK, Michel MK, Cha E, et al. Analysis of insecticide-treated net use by pregnant women: implications for donor organizations. J Lifestyle Med. 2016;6:36-42.

21. Obol JH, Ononge S, Orach CG. Utilisation of insecticide treated nets among pregnant women in Gulu: a post conflict district in northern Uganda. Afr Health Sci. 2013;13:962-9.

22. Brooks HM, Paul MKJ, Claude KM, Mocanu V, Hawkes MT. Use and disuse of malaria bed nets in an internally displaced persons camp in the Democratic Republic of the Congo: a mixed-methods study. PLoS ONE. 2017;12:e0185290.

23. Ouedraogo M, Kurji J, Abebe L, Labonté R, Morankar S, Bedru KH, et al. Utilization of key preventive measures for pregnancy complications and malaria among women in Jimma Zone, Ethiopia. BMC Public Health. 2019:19:1443.

24. Uganda Bureau of Statistics, ICF. Uganda Demographic and Health Survey. Rockville. USA: Kampala, Uganda; 2016. p. 2018.

25. Arthur E. Wealth and antenatal care use: implications for maternal health care utilisation in Ghana. Health Econ Rev. 2012;2:14.

26. Tarekegn SM, Lieberman LS, Giedraitis V. Determinants of maternal health service utilization in Ethiopia: analysis of the 2011 Ethiopian Demographic and Health Survey. BMC Pregnancy Childbirth. 2014;14:161.

27. Sangaré LR, Weiss NS, Brentlinger PE, Richardson BA, Staedke SG, Kiwuwa MS, et al. Determinants of use of insecticide treated nets for the prevention of malaria in pregnancy, Jinja, Uganda. PLoS One. 2012;7:e39712.

\section{Publisher's Note}

Springer Nature remains neutral with regard to jurisdictional claims in published maps and institutional affiliations.

Ready to submit your research? Choose BMC and benefit from

- fast, convenient online submission

- thorough peer review by experienced researchers in your field

- rapid publication on acceptance

- support for research data, including large and complex data types

- gold Open Access which fosters wider collaboration and increased citations

- maximum visibility for your research: over 100M website views per year

At $\mathrm{BMC}$, research is always in progress.

Learn more biomedcentral.com/submissions 